\title{
OS ADJUNTOS TEMPORAIS NA PERSPECTIVA DA CARTOGRAFIA SINTÁTICA E DA SEMÂNTICA DE EVENTOS ${ }^{1}$
}

\author{
("TEMPORAL ADJUNCTS FROM A CARTOGRAPHIC SYNTAX \\ AND EVENT SEMANTICS PERSPECTIVE")
}

\author{
JOÃO FRANCISCO BERGAMINI-PEREZ ${ }^{2}$ \\ AQUILES TESCARI NETO ${ }^{3}$
}

\begin{abstract}
RESUMO
O estudo dos sintagmas adverbiais é um produtivo campo para o desenvolvimento de pesquisas no âmbito da sintaxe a semântica das línguas naturais. Os adjuntos temporais, como "em x tempo" e "por x tempo", mesmo que já bastante descritos pela literatura, ainda carecem de uma descrição mais aprofundada quando se busca entender de que maneira podem influenciar as possíveis interpretações das sentenças em que estão presentes. Tendo isso em mente, o objetivo principal deste artigo é propor uma análise que, ao considerar a metodologia da Cartografia Sintática e da Semântica de Eventos, capture a contribuição do adjunto temporal - mais especificamente do adjunto "em x tempo" - em sentenças do português brasileiro, bem como, argumentar a favor de uma hipótese segundo a qual os traços dos adjuntos temporais sejam valorados em mais de uma posição da hierarquia universal.

Palavras-chave: adjuntos temporais; cartografia sintática; semântica de eventos.
\end{abstract}

\begin{abstract}
The study of adverbial phrases is a productive field for research developments in the syntax and the semantics of natural languages. Although the Brazilian Portuguese temporal adjuncts "em x tempo" ("in x time") and "por x tempo" ("for x time") are relatively well described in the literature, they still need an in-depth study when one tries to understand the possible interpretations of the sentences where they are present. Having that in mind, the main goal of this paper is to develop a Cartographic and Event Semantics analysis able to capture the contribution of the temporal adjunct-more specifically "em x tempo" ("in x time") — in Brazilian Portuguese sentences. Besides that, it also aims at arguing in favor of a hypothesis by which the features of temporal adjuncts be valued in more than one position in the universal hierarchy.
\end{abstract}

Keywords: temporal adjuncts; syntactic cartography; event semantics.

${ }^{1}$ Agradecemos aos dois pareceristas da Cadernos pelas valiosas contribuições. Agradecemos também a leitura e os comentários de Renato Miguel Basso a uma primeira versão do texto. O trabalho foi inicialmente apresentado no III CSR, ocorrido na UFSCar em agosto de 2019. Nosso "obrigado" vai também aos valiosos questionamentos que lá nos foram colocados. Os erros que persistirem são naturalmente nossos. O primeiro autor agradece à FAPESP pelo auxílio vinculado a essa pesquisa (Processo 2018/24960-7).

2 LaCaSa - Laboratório de Cartografia Sintática: Pesquisa e Ensino (https://is.gd/ LaCaSaUnicamp).jfbergaminiperez@gmail.com Orcid: https://orcid.org/0000-0001-9191-3902

${ }^{3}$ LaCaSa - Laboratório de Cartografia Sintática: Pesquisa e Ensino. tescari@unicamp.br Orcid: https://orcid.org/0000-0002-8157-3921 


\section{INTRODUÇÃO}

Os advérbios - ou, mais precisamente, os adjuntos adverbiais - são utilizados dentro das propostas gerativistas como base para identificar o movimento do verbo à flexão, uma vez que se assume que esses elementos ocupam posições fixas na estrutura sintática e que o verbo se movimenta por sobre eles em IP (cf. Emonds, 1978; Pollock, 1989; Belletti, 1990; Galves, 2001; Silva, 2001; Tescari Neto, 2013; dentre tantos outros).

Com essa premissa em mente e, considerando o Programa Cartográfico, temos, na literatura-base, dois conjuntos de classes de advérbios que são utilizados como diagnósticos de movimentos, descritivamente chamados de advérbios altos e baixos. Os advérbios altos são os que ocupam posições mais altas na estrutura sintática e, consequentemente, são menos propensos, em línguas românicas como o português brasileiro e o europeu, a serem ultrapassados pelo verbo temático finito (pelo menos a julgar por Tescari Neto (2013, cap. 5)). ${ }^{4}$ Já os advérbios baixos, como o próprio nome diz, são os que ocupam posições mais baixas na estrutura sintática, sendo considerados mais confiáveis para identificar os movimentos do verbo na estrutura de IP (Galves, 2001), sendo tais considerações já aceitas pelo menos desde Pollock (1989). Podemos exemplificar essas observações considerando as sentenças abaixo, que exemplificam o movimento do verbo na sentença (2):

1. ${ }^{? *}$ A Tamara completamente acabou a lição de casa.

2. A Tamara acabou completamente a lição de casa.

Podemos ver, nos exemplos acima, que a sentença gramatical é a que conta com a subida do verbo por sobre o advérbio (nomeadamente a sentença (2)) para uma posição intermediária na estrutura sintática, ou melhor, para uma posição em IP.

Como nosso objetivo principal neste trabalho é, tomando como base o Programa Cartográfico (sobretudo a versão de Cinque (1999)), avançar uma (primeira) análise sobre a posição (ou posições) ocupada(s) pelos adjuntos temporais de medida do tipo de em $\times$ tempo $o^{5}$ na estrutura sintática, mostraremos, em um primeiro momento, as contribuições semânticas dos adjuntos temporais em sentenças do português brasileiro. Focaremos, para isso, no adjunto temporal "em x tempo". Posteriormente, apresentaremos, de maneira sucinta, as bases epistemológicas e metodológicas do Programa Cartográfico para, na sequência, argumentar que os traços dos adjuntos temporais de medida são valorados em mais de uma posição da hierarquia universal (de acordo com o que chamaremos de "hipótese B"), não estando, portanto, envolvida, na história derivacional desses adjuntos, uma única posição sintática ("hipótese A").

${ }^{4}$ Análise distinta é empreendida em Schifano (2018).

${ }^{5}$ A exemplo dos estudados em Basso e Bergamini-Perez (2017) e Basso e Bergamini-Perez (2016), do tipo de em dez minutos, em quinze anos, etc. 


\section{ADJUNTOS TEMPORAIS DE MEDIDA}

Tendo uma estrutura sentencial formada por [Agente + Verbo (Aspecto Perfectivo/Pretérito Perfeito do Indicativo], como (3) e (4) a seguir,

\section{João lavou a louça.}

4. A menina ganhou o jogo.

é possível notar que, somente por estar no [Aspecto Perfectivo/Pretérito Perfeito do Indicativo], temos como interpretações preferenciais as de que João tenha acabado de lavar a louça (caso da sentença (3)) e de que a menina tenha terminado, com vitória, o jogo (sentença 4). Noutras palavras, considerando as sentenças (3) e (4), somente pelas informações dadas por Aspecto/Tempo, já é possível alcançar a interpretação de que o evento cessou, ou seja, a interpretação de que o evento denotado pelo predicado verbal não está mais em andamento. Contudo, é importante salientarmos que, na sentença 3, também é possível a emergência de uma interpretação segundo a qual não temos necessariamente que o telos tenha sido alcançado, uma vez que é possível fazer a construção "João lavou a louça, mas deixou as panelas de molho com os talheres dentro". Ou seja, o evento "lavar a louça" cessou, mas não teve seu telos alcançado ${ }^{6}$.

Como se vê, temos uma diferença nas possíveis interpretações entre os verbos que podem ser classificados por certos traços que os caracterizam. Para identificar tais diferenças ou semelhanças, tomamos como base o trabalho de Vendler (1957). $\mathrm{O}$ autor propõe quatro tipos de eventos distintos, categorizados a partir de traços acionais (as conhecidas classes vendlerianas), conforme vemos no quadro 1, a seguir.

\begin{tabular}{|l|l|l|l|}
\hline & [durativo] & [télico] & [dinâmico] \\
\hline accomplishments & + & + & + \\
\hline achievements & - & + & + \\
\hline estativos & + & - & - \\
\hline atividades & + & - & + \\
\hline
\end{tabular}

Quadro 1. Classes vendlerianas e seus respectivos traços acionais ${ }^{7}$

${ }^{6} \mathrm{O}$ aspecto perfectivo, em português brasileiro, se refere ao evento que não continua mais "cessou" ou "terminou" -, podendo ter duas possibilidades: i. o evento alcançou seu telos; ou ii. o evento parou. A ocorrência "João lavou a louça" é, portanto, compatível com as duas situações, tanto uma em que "João lavou a louça até às 14 horas" - não sendo possível afirmar se o evento terminou ou não - quanto uma em que "João lavou a louça em 40 minutos" - i.e., terminou de lavar tudo. O aspecto perfectivo por si só não fornece a informação de que o evento denotado por VP tenha cessado ou terminado. Essa segunda possibilidade é a que Basso (2007) chamou de "detelicização": eventos télicos perfectivos, mas que não têm o alcance do telos garantido.

${ }^{7}$ Adaptado de Basso e Bergamini-Perez, 2016, p. 348. 
Em nosso trabalho, consideraremos os eventos do tipo accomplishment e achievement, por serem ambos télicos e apresentarem diferenças em seu caráter durativo.

Quando nos referimos aqui aos adjuntos temporais de medida, consideramos uma estrutura básica: aquela formada por [preposição + sintagma de medida], como “em x tempo" ("em 10 minutos"), "por x tempo" ("por 10 minutos"), "durante x tempo" ("durante 10 minutos"), etc. ${ }^{8}$ Temos que cada um desses adjuntos temporais traz uma contribuição distinta para a sentença; assim, o adjunto "em $\mathrm{x}$ tempo", por exemplo, fornece um ponto específico no qual o evento cessou e teve seu telos alcançado:

5. Tamara fez a apresentação em 20 minutos.

6. O maratonista cruzou a linha de chegada em 1 hora.

Para ambas as sentenças com o adjunto em posição default ${ }^{9}$, temos uma interpretação télica mais saliente: aquela em que o telos do evento télico é marcado e reforçado pela presença do adjunto temporal de medida ("em x tempo"), que indica o ponto exato em que o evento alcançou seu fim e, também, seu telos.

O adjunto temporal "por x tempo", por sua vez, fornece uma medida para a duração do evento denotado pelo predicado verbal, ou seja, não faz referência a um alcance do término/fim do evento:

7. Tamara lavou a louça por 20 minutos.

8. O Brasil ganhou o jogo por 30 minutos.

Em ambos os casos, temos que o adjunto temporal de medida somente fornece uma duração para o evento denotado. Noutras palavras, o evento cessou, mas não necessariamente alcançou seu telos.

Em vista do nosso objetivo - o de avançar uma análise que capture a posição, ou melhor, as posições (conforme argumentaremos adiante) dos adjuntos temporais acima descritos, consideraremos, no presente trabalho, somente o adjunto temporal de medida "em x tempo". Tal recorte é feito em virtude do fato de "em x tempo" (i) ser um adjunto bastante descrito pela literatura e (ii) por fazer emergir a chamada leitura incoativa, detectada em (9b):

9a. Tamara lavou a louça em 20 minutos.

9b. Tamara em 20 minutos lavou a louça.

${ }^{8}$ Ver Basso e Bergamini-Perez (2016) para uma descrição, na perspectiva da Semântica de Eventos, desses três tipos de adjuntos temporais.

${ }^{9}$ Chamaremos de posição default aquela na qual o adjunto temporal de medida está em sua posição canônica, i.e., em posição pós-verbal no final da sentença: "Carla dirigiu por 2 horas", "O menino fez a prova do ENEM em 3 horas", etc. 
Em ambas as sentenças temos como preferencial a leitura télica com a marcação do telos do evento ${ }^{10}$. Contudo, na sentença ( $9 \mathrm{~b}$ ), temos a possibilidade de uma interpretação incoativa ${ }^{11}$, que pode ser descrita pela seguinte paráfrase "Tamara levou 20 minutos para começar a lavar a louça"12: nesta interpretação não se fala mais em relação ao final do evento denotado pelo predicado verbal, mas, sim, do fim dos $n$ eventos anteriores ao início do predicado referenciado na sentença. É interessante ainda notar que tal possível leitura não surge com eventos do tipo achievement, como nos exemplos abaixo:

10a. O Brasil ganhou o jogo em 30 minutos.

10b. O Brasil em 30 minutos ganhou o jogo.

Independentemente da posição em que o adjunto temporal é linearizado, temos a mesma interpretação télica.

A leitura incoativa dos accomplishments e a leitura télica dos achievements têm grande semelhança; contudo, a diferença reside na maneira como ocorre o alcance do telos em cada combinação. Para a leitura télica dos achievements, o alcance do telos é do predicado veiculado na sentença base - no caso das sentenças (10a) e (10b), o predicado "ganhar o jogo"; já para a leitura incoativa dos accomplishments, o alcance do telos é referente aos eventos anteriores ao denotado pelo predicado verbal da sentença - no exemplo 9b, o fim dos eventos que precedem o início de "lavar a louça". ${ }^{3}$

Com essas singularidades pontuadas, podemos dizer que essa diferença entre as possíveis interpretações dos dois tipos de eventos considerados talvez possa ter relação com seu traço de duratividade, pois ambos são eventos télicos, mas um

${ }^{10}$ As sentenças não apresentam uma interpretação default, mas sim, interpretações mais salientes. Assim, na sentença (9a), p.ex., a interpretação télica parece ser a mais saliente. O que se considera aqui como default é a posição ocupada pelo adjunto. No caso, a posição default é aquela em que o adjunto temporal de medida se encontra no final da sentença, como comentado na nota de rodapé 9, e exemplificado pela sentença (9a).

${ }^{11}$ A leitura incoativa também é alcançada na combinação do adjunto temporal de medida "em $\mathrm{x}$ tempo" com eventos atélicos (por exemplo, eventos do tipo atividades), como em "João jogou basquete em 10 minutos". Contudo, focaremos nossa discussão na leitura incoativa para os accomplishments.

${ }^{12}$ Se considerarmos um contexto em que Tamara chegou do trabalho, trocou de roupa, comeu algo - tendo isso levado 20 minutos - e, depois, lavou a louça, então a leitura incoativa para a sentença "Tamara em 20 minutos lavou a louça" parece ser possível.

${ }^{13}$ É importante salientarmos, mesmo de maneira sucinta, que a leitura incoativa é possível para eventos do tipo atividade e semelfactivo, como vemos em (i) e (ii):

i. João nadou em 10 minutos (atividade)

ii. Tamara espirrou em 5 minutos (semelfactivo)

Tal leitura parece ter relação ao traço de duratividade ligado a esses dois tipos de evento. Noutras palavras, independentemente da posição do adjunto temporal na estrutura da sentença, quando esses eventos se combinam com o adjunto temporal "em x tempo", a leitura incoativa parece ser preferencial, tornando possíveis as paráfrases (i') e (ii'), respectivamente, para os exemplos citados acima:

i'. João levou 10 minutos para começar a nadar

ii’. Tamara levou 5 minutos para começar a espirrar. 
se caracteriza por um traço de duratividade positivo (accomplishments) e outro por um traço negativo (achievement) - em termos das classes acionais de Vendler (1957), cf. quadro 1, acima -. A partir disso, podemos fazer uma conexão entre as contribuições semânticas trazidas até aqui com a sua contraparte sintática.

\section{A CARTOGRAFIA SINTÁTICA E OS ADJUNTOS TEMPORAIS}

Este trabalho tem suas bases no Programa Cartográfico (Cinque, 1999, 2004, 2006; Rizzi, 1997, 2004; dentre outros), vertente da Teoria de Princípios e Parâmetros da Gramática Gerativa. O Programa Cartográfico tem como diretrizmetodológica de base o princípio do "One feature, one head" (Kayne, 2005) - "um traço, um núcleo' -, segundo o qual as categorias do sistema conceitual (categorias semânticas e pragmáticas) são "sintatizáveis", isto é, correspondem a um núcleo funcional no componente sintático. Com isso em mente, no que tange aos adjuntos temporais de medida poderíamos lançar duas hipóteses para seu posicionamento na estrutura: a hipóteses A e B. Vamos favorecer, no decorrer da argumentação, a hipótese $B$.

Pela hipótese $A$, a interpretação dos adjuntos temporais de medida levaria em conta uma única posição de Soldagem ('Merge') - e, nesse caso, os adjuntos temporais de medida teriam posições únicas de Soldagem na estrutura -, se existem de fato posições na hierarquia universal (de Cinque (1999)) para os adjuntos temporais de medida. Por essa hipótese, então, os adjuntos de medida temporal valorariam, por Soldagem, seu traço na posição em que entrariam na derivação, não sendo necessário nenhum movimento ulterior (deles ou de porções da estrutura - p.ex., o VP) para garantir as interpretações a eles associadas, descritas na seção anterior.

A hipótese B - em favor da qual argumentaremos neste trabalho - entende que a interpretação dos adjuntos temporais de medida envolveria a valoração de mais de uma categoria da hierarquia sintática. Por essa hipótese, então, os adjuntos temporais de medida seriam "categorias derivadas", no sentido em que seriam um produto de operações de Soldagem e Movimento, com as valorações, em posições específicas da hierarquia universal de Cinque (1999), dos traços associados aos adjuntos de medida temporal. ${ }^{14,15}$

${ }^{14} \mathrm{~A}$ análise cartográfica que aqui desenvolvemos para os adjuntos de medida temporal - que não os considera categorias primitivas, mas derivadas - guarda semelhanças com a abordagem de Lima (2020) à expressão do que o autor chama de "exclamatividade- $w h$ ".

${ }^{15}$ Muito embora a priori possa parecer econômico recorrer tão somente à Soldagem (externa) - no que diz respeito ao mapeamento das estruturas sintáticas à interface com o sistema conceitual -, e, portanto, criar mais uma nova categoria para garantir as interpretações associadas aos adjuntos de medida temporal (discutidas na seção anterior) (tal como previsto pela "Hipótese A"), tal hipótese, na verdade, é muito menos econômica por prever que, para cada interpretação, teríamos de ter uma única posição específica e, mais do que isso, uma nova categoria. A hipótese B é a mais econômica por permitir que, recorrendo tão somente às categorias da hierarquia universal, as estruturas sejam mapeadas à interface com o sistema conceitual tão somente a partir de mecanismos sintáticos básicos (soldagem e movimento). A hipótese A, p.ex., nos faria "criar" novas categorias às quais não disporíamos sequer de evidência tipológica independente. Vale lembrar que, segundo Chomsky 
Deste modo, tanto a hipótese A quanto a B levam em conta a hierarquia universal de Cinque (representada na fig. 1, a seguir). A diferença entre as duas abordagens reside nos mecanismos derivacionais que garantirão, em LF, a interpretação associada aos adjuntos temporais de medida: ou sua intepretação estaria associada diretamente à posição em que seriam Soldados externamente (hipótese A) ou sua interpretação se daria pela valoração dos traços associados a diferentes posições da hierarquia sentencial, garantidos por Soldagem e movimento (hipótese B). A figura 1, a seguir, apresenta as projeções da hierarquia de Cinque, posições essas que, conforme argumentaremos na sequência, estão diretamente associadas à interpretação dos adjuntos temporais de medida aqui estudados:

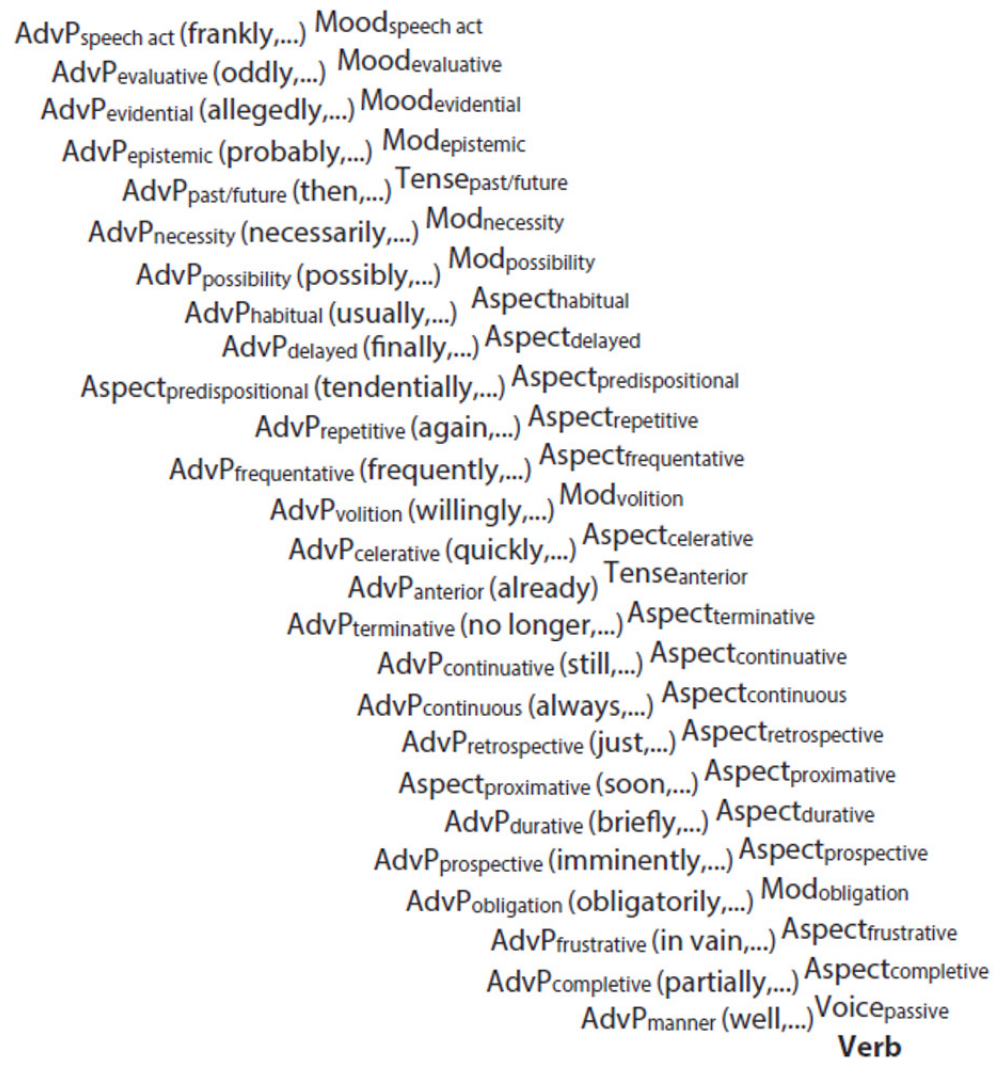

Figura 1. A estrutura do Middlefield de Cinque (1999)

(Fonte: adaptado de Rizzi; Cinque, 2016, p. 150)

(1995: 240) "[a] postulação de uma categoria funcional deve ser justificada, seja por condições de saída (interpretação fonética e semântica) ou por argumentos internos da teoria." A hipótese B atende plenamente essa diretriz minimalista - já por não recorrer a nenhuma nova categoria (diferentemente da hipótese A) -, sendo, portanto, também sob esse viés, uma proposta mais econômica. 
A hierarquização das categorias funcionais em posições rígidas na estrutura do Middefield, como mostrada na figura 1, segue uma metodologia bem simples, proposta por Cinque (1999). Basicamente, por testes de precedência e transitividade dos diferentes advérbios (AdvPs) combinados entre si, vemos que cada um deles apresenta uma posição específica em relação aos outros. Essas posições formam, ao fim, a hierarquia mostrada acima.

Tomando, por exemplo, o AdvPepistêmico "provavelmente" e o AdvPcontínuo "sempre", "provavelmente" precede "sempre": se combinarmos os dois advérbios na mesma sentença é esperado que a ocorrência seja possível com o "provavelmente" aparecendo antes do "sempre"16, como vemos a seguir:

\section{1a. Luigi provavelmente sempre come ração com petisquinhos.}

11b. *Luigi sempre provamelmente come ração com petisquinhos.

Como podemos ver nos exemplos acima, a sentença (11a), mas não a (11b), é bem formada, coadunando com o que já esperávamos pela hierarquia dos advérbios, proposta por Cinque (1999).

Tomando, então, as categorias da estrutura dada pela figura 1, bem como os conceitos usados como base para esta hierarquização, como mostrado brevemente, podemos dizer que existem duas posições hierárquicas correspondentes ao traço de telicidade na hierarquia oracional:

- Asp. Terminativo: (não...mais) marca o fim de um evento télico ou atélico (bounded/unbounded) em um ponto arbitrário: "stop", "quit", "cease". O $\mathrm{Asp}_{\text {Terminativo }}$ está acima dos $\mathrm{Asp}_{\text {Completivo }}$ I e II. O Asp $\mathrm{Aerminativo}$, diferentemente dos completivos, expressa a finalização de um certo processo ou estado em um ponto arbitrário, ao invés de seu ponto final natural do processo, quando há um;

-Asp. Completivo: (finished/end) marca o fim de um evento télico (bounded) em seu ponto-final natural: "terminar". $\mathrm{O}$ aspecto completivo tem duas posições na estrutura, uma de completivo plural (cujo advérbio representante da classe é o advérbio tudo) e uma de completivo singular (cujo especificador é ocupado pelo advérbio completamente). ${ }^{17}$

Os ingredientes derivacionais que garantirão as interpretações descritas na seção anterior envolvem, para além da soldagem do adjunto temporal de medida em posição dedicada acima de $\nu \mathrm{P}$, nomeadamente no especificador do circunstancial temporal (conforme Cinque (2006)), o movimento do VP, que valorará o traço do núcleo em cujo especificador pousará. O predicado (VP) que denota um evento do tipo accomplishment, por ser télico durativo $(+t,+d)$, deve passar por

${ }^{16}$ Ver Tescari Neto $(2013,2015)$ para casos em que aparentemente (somente aparentemente) a hierarquia é violada.

${ }^{17}$ Desconsideraremos aqui a diferença entre AspCompletivo I e II, uma vez que temos como objetivo enfatizar a contribuição do núcleo funcional AspCompletivo na estrutura, em comparação com o AspTerminativo. 


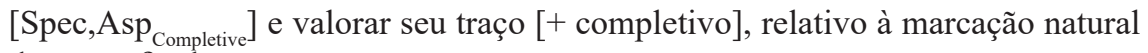
de ponto final.

Predicados (VP) que denotam eventos do tipo achievement, télicos nãodurativos $(+\mathrm{t},-\mathrm{d})$ - como o da sentença (4) da seção anterior, abaixo reproduzido -, também valoram seu traço télico em [Spec,Asp Completive $_{\text {] }}$, indicando que o VP tem traço semântico relativo à finalização do evento, ou seja, revelando que o evento acabou e seu telos foi alcançado.

(4) A menina ganhou o jogo.

Contudo, predicados (VP) que denotam eventos do tipo accomplishment (ver sentença (3) da seção anterior, reproduzida a seguir por conveniência), como comentado anteriormente, podem também fazer emergir uma interpretação segundo a qual o evento cessou em algum ponto arbitrário, mas não necessariamente que o telos tenha sido alcançado. Isto é, o VP relacionado a este tipo de evento pode

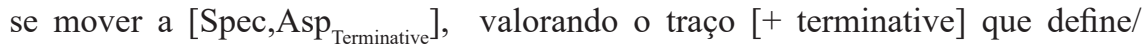
justifica essa projeção (no espírito do princípio do "One feature, one head"), o que é diferente para o caso do VP que denota um achievement, para o qual tal possibilidade não existe, como já mostramos anteriormente na breve argumentação das sentenças (3) e (4) da seção anterior. Esta discussão será bem exemplificada mais à frente, quando faremos uma proposta inicial sobre como o VP que denotada cada evento valora os traços envolvidos na interpretação da sentença, à medida em que sobe na estrutura do Middlefield.

\section{(3) João lavou a louça.}

Para estarmos de acordo com a ideia de hierarquização dos advérbios de Cinque, seja para fomentar uma posição específica para o adjunto temporal "em x tempo" ou para mostrar que pode ser uma categoria derivada (no espírito da hipótese B), devemos fazer alguns testes que determinem o posicionamento desse adjunto temporal em comparação e combinação com outros advérbios da estrutura - o que é feito nas sentenças em (12-16), a seguir. Nota-se, pelos exemplos abaixo e sua posterior discussão, que o adjunto temporal de medida parece poder se mover por entre os advérbios baixos, acompanhando o VP com o qual se solda. Consideramos, então, que a interpretação veiculada pelo adjunto temporal de medida seja - de acordo com a hipótese B - um produto de operações sintáticas de Soldagem e Movimento, com as devidas valorações dos traços associados em posições específicas da hierarquia da fig. $1 .^{18}$

${ }^{18}$ A interpretação relevante em (12-15) é a que tem como referência o tempo do evento denotado pelo predicado, o que fica claro pelas ocorrências em $(c)$ : $(12 \mathrm{c}, 13 \mathrm{c}, 14 \mathrm{c} \wedge 15 \mathrm{c})$. Nesse sentido, o escopo de provavelmente e de obrigatoriamente a ser considerado nesses exemplos é "estreito", i.e., por sobre em 20 minutos. 
12a. João fez a lição de casa em 20 minutos.

12b. *João fez a lição de casa em 20 minutos provavelmente. ${ }^{19}$

12c. João fez a lição de casa provavelmente em 20 minutos. ${ }^{20}$

12d. João em 20 minutos provavelmente fez a lição de casa. ${ }^{21}$

12e. João provavelmente em 20 minutos fez a lição de casa.

13a. O Brasil ganhou o jogo em 30 minutos.

13b. *O Brasil ganhou o jogo em 30 minutos provavelmente.

13c. O Brasil ganhou o jogo provavelmente em 30 minutos.

13d. O Brasil em 30 minutos provavelmente ganhou o jogo.22

13e. O Brasil provavelmente em 30 minutos ganhou o jogo.

14a. João fez a lição de casa em 20 minutos.

14b. João fez a lição de casa em 20 minutos obrigatoriamente.

14c. João fez a lição de casa obrigatoriamente em 20 minutos.

14d. João em 20 minutos obrigatoriamente fez a lição de casa. ${ }^{23}$

14e. João obrigatoriamente em 20 minutos fez a lição de casa.

15a. O Brasil ganhou o jogo em 30 minutos.

15b. O Brasil ganhou o jogo em 30 minutos obrigatoriamente.

15c. O Brasil ganhou o jogo obrigatoriamente em 30 minutos.

15d. O Brasil em 30 minutos obrigatoriamente ganhou o jogo.

15e. O Brasil obrigatoriamente em 30 minutos ganhou o jogo.

16a. João fez a lição de casa em 20 minutos.

16b. *João fez a lição de casa em 20 minutos rapidamente.

16c. João fez a lição de casa rapidamente em 20 minutos.

${ }^{19}$ Essa sentença é somente possível com uma marcação prosódica nítida, isolando o advérbio provavelmente do resto da sentença. Nesse caso, a ocorrência teria uma derivação similar a (12e), com a diferença de que haveria movimento ulterior do advérbio provavelmente para [Spec,ModP] (de Rizzi, 2004) e ulterior movimento do remanescente a [Spec,TopP]. A mesma observação vale para (13b).

${ }^{20}$ A interpretação a ser considerada em (12c) é aquela segundo a qual provavelmente tem escopo estreito, i.e., escopo por sobre em 20 minutos. A mesma observação vale para (13c, 14c, 15c).

${ }^{21}$ Devemos ter cuidado com este exemplo, uma vez que o escopo de "provavelmente", aqui, é o VP/o evento "fazer a lição de casa", não o tempo relacionado à sentença. Vide nota 17.

${ }^{22}$ A mesma consideração feita para o exemplo 12 d é válida a este exemplo.

${ }^{23}$ A mesma consideração feita para o exemplo 12d, com relação ao advérbio "provavelmente", deve ser considerada a este exemplo com o advérbio "obrigatoriamente". 
16d. João em 20 minutos rapidamente fez a lição de casa. ${ }^{24}$

16e. João rapidamente em 20 minutos fez a lição de casa.

Podemos continuar estes testes de posicionamento, considerando advérbios que estejam entre $A_{\text {spompletive }}$ e $A_{\text {serminative }}$ (na hierarquia de Cinque), para determinar a posição do adjunto temporal. Os testes revelam que o adjunto temporal tem um limite de subida (uma posição máxima a que pode se mover), nomeadamente $\mathrm{Asp}_{\text {Terminative }}$, pois, como podemos ver nos testes com advérbios que se situam acima deste núcleo funcional (exemplos 12b e 13b), a sentença é agramatical. ${ }^{25}$ Isso pode ser um indício de que a preposição "em" não tenha uma posição fixa de Soldagem, podendo ser soldada em mais de uma posição sintática dentro da estrutura; contudo, o núcleo funcional relativo à preposição "em" obrigatoriamente terá vinculado a si o traço ligado à telicidade: "em" poderia se encontrar em $\operatorname{Asp}_{\text {Terminative }}{ }^{0}$ ou $\operatorname{Asp}_{\text {Completive }}{ }^{0}$, trazendo a mesma contribuição semântica que é a de fornecer um ponto final ao evento. Como consideramos o princípio do "One feature, one head" (Kayne, 2005), favorecemos a hipótese $\mathrm{B}$, segundo a qual o adjunto temporal não tem uma posição dedicada, única na estrutura hierárquica ${ }^{26}$; antes, SMs temporais fazem sua primeira Soldagem no especificador do circunstancial de tempo ([Spec,TempP]) - abaixo, portanto, do advérbio mais baixo da hierarquia universal (cf. Cinque, 2006, cap. 6) $)^{27}-$ como um $\mathrm{PP}^{28}$, e movimentos posteriores do VP (no modo whose-pictures de piedpiping, à la Cinque (2006, 2017), i.e., com inversão da ordem dos argumentos e dos adjuntos) garantem a valoração/checagem dos traços associados à interpretação do adjunto temporal, como podemos exemplificar, sucintamente, pela figura 2 , a seguir, que ilustra a história derivacional de $(17)^{29}$ :

${ }^{24}$ Devemos nos atentar ao fato de que o escopo de "rapidamente", aqui, é o VP "fazer a lição de casa", não tendo relação com o tempo tomado pelo evento.

${ }^{25}$ A agramaticalidade de $(12 \mathrm{~b}, 13 \mathrm{~b})$ é um argumento favorabilíssimo à "hipótese B": sendo a posição de Soldagem de provavelmente muito acima de $\mathrm{Asp}_{\text {Terminative }}$, tais ocorrências não seriam sequer deriváveis no espírito da hipótese $\mathrm{B}$.

${ }^{26}$ Estamos considerando as ideias e testes, bem como a contribuição do adjunto temporal em comparação com os outros advérbios, que foram feitos até este momento da pesquisa. Talvez, a partir de um aprofundamento da questão, diagnósticos futuros poderão hierarquizar os adjuntos temporais dentro da estrutura do Middlefield ou, então, oferecer argumentos ainda mais favoráveis à hipótese B.

${ }^{27}$ Não vamos avançar aqui uma discussão sobre a zona de Soldagem dos adjuntos circunstanciais relativamente aos argumentos do $\mathrm{V}$ e os advérbios da hierarquia de Cinque, para o que remetemos o leitor a Cinque (2006, capítulo 6) e a Tescari Neto (2019).

${ }^{28} \mathrm{Ou}$, até mesmo, partindo de uma estrutura AxParT, como mostrado por Roy e Svenonius (2009) - algo que será analisado posteriormente.

${ }^{29}$ Agradecemos aos pareceristas pelas importantes observações feitas. As sentenças analisadas no decorrer do trabalho levam em conta as possibilidades de interpretação indicadas por nós (no próprio texto ou em nota). Não são necessariamente as únicas interpretações possíveis, pelas razões relacionadas, p.ex., ao escopo dos adjuntos envolvidos - fato apontado em várias notas de rodapé, acima. Estamos cientes das possíveis diferenças quanto ao julgamento de gramaticalidade de algumas sentenças, a depender das diferentes gramáticas (línguas- $I$ ) consideradas. Esse fato, contudo, não desmerece o ponto principal do trabalho, que é mostrar como as interpretações associadas aos adjuntos temporais de medida já são mapeadas pela Narrow Syntax ao sistema conceitual. 
17. João lavou a louça em 10 minutos.

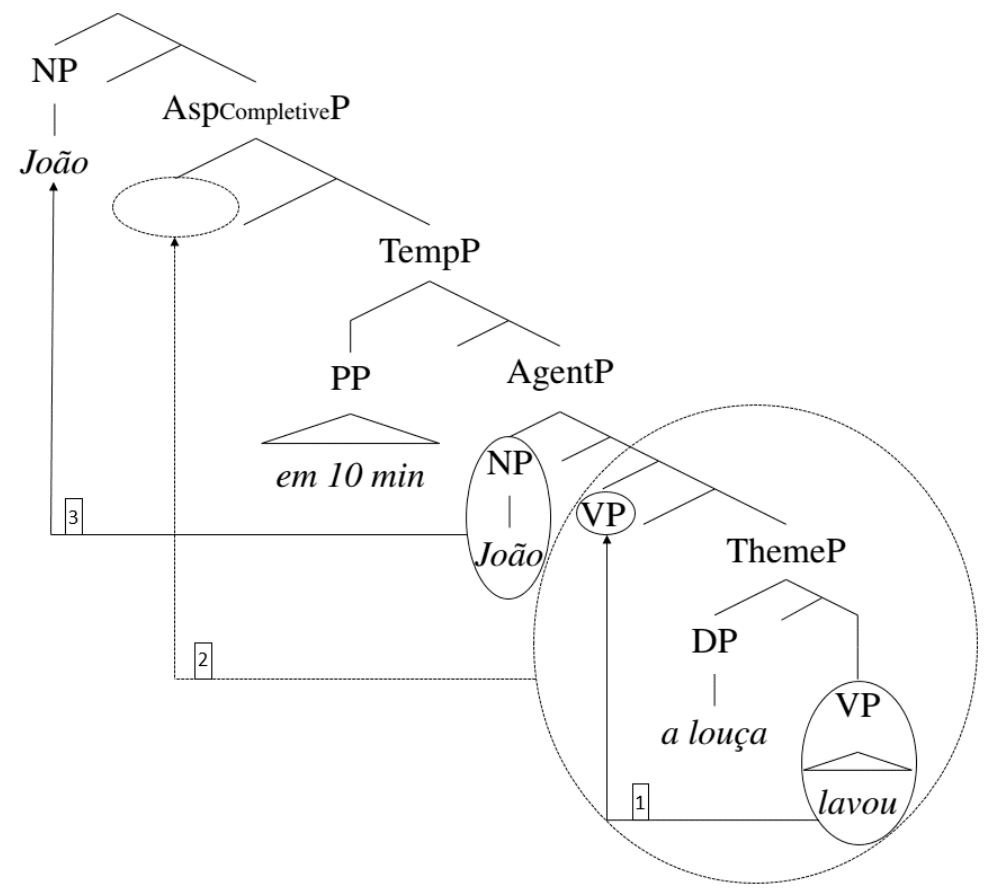

Figura 2. Da derivação de (17)

Fonte: elaboração própria

Considerando, então, a sentença (17), cuja derivação é esboçada na figura 2, temos que o evento denotado pelo predicado verbal (VP) "lavar a louça" (télico durativo $[+\mathrm{t},+\mathrm{d}])$, no aspecto perfectivo e pretérito perfeito, tem esses dois traços valorados através de movimento de $\mathrm{VP}$ a $\left[\mathrm{Spec}, \mathrm{Asp}_{\text {Completive }}\right]$ e $\left[\mathrm{Spec}, \mathrm{Asp}_{\text {Terminative }}\right]$. O núcleo funcional dessas duas projeções traz consigo uma contribuição semântica diferente para o traço de telicidade. Na esteira de Cinque (2006), assumimos que o VP entra na estrutura, soldando-se com o núcleo em cujo especificador é soldado o DP-tema "a louça". O VP se move por sobre o DP-tema, invertendo a ordem de Soldagem desses dois elementos. Na sequência, o NP-agente "João" é soldado no especificador da projeção de AgentP, em consonância com Cinque (2006). É hora de o núcleo licenciador do circunstancial temporal se soldar à estrutura. Em seu especificador, é soldado o PP temporal "em dez minutos". À projeção TemP é soldado o núcleo do aspecto completivo e o VP se move a seu especificador -

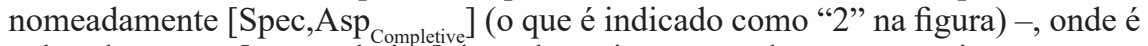
valorado o traço [+ completive] daquela projeção, que denota semanticamente que o evento cessou e seu telos foi alcançado. Contudo, devido à combinação deste VP com o adjunto temporal "em 10 minutos" ${ }^{30}$, em posição default, um outro movimento de VP para a posição de $\left[\mathrm{Spec}, \mathrm{Asp}_{\text {Terminative }}\right]$ com checagem do traço

${ }^{30}$ Como já discutido anteriormente, exemplos (5) e (6), o adjunto temporal "em x tempo" determina um ponto exato onde ocorre o fim ou alcance do telos do evento. 
[+terminative] não é permitido, pois o adjunto temporal "em 10 minutos" fornece o ponto exato em que o evento alcançou seu telos, isto é, não existe a possiblidade de que VP, por subida, continue para uma posição na qual o evento somente cessou em um ponto arbitrário. Ou melhor, o evento de "lavar a louça" feito por João alcançou seu telos no ponto exato dado pelo adjunto temporal de medida "em 10 minutos", ou então, "João lavou a louça em 10 minutos". As etapas relevantes à interpretação do adjunto temporal são as aqui descritas. Posteriormente, o NP "João" se move à posição de sujeito (passo aqui indicado como 3). ${ }^{31}$

Para a leitura incoativa, alcançada com os eventos do tipo accomplishment, temos na hierarquia sintática do Middlefield, duas posições relativas a essa possível interpretação, que são:

\section{-Asp. Inceptivo: ${ }^{32}$}

- Inceptivo I - marca o começo de um evento télico ou atélico em um ponto arbitrário: "começar a fazer a barba" ou "começar a cantar uma melodia". (start)

- Inceptivo II - marca o início de um evento télico em seu ponto inicial natural: "começar a construir uma casa" ou "começar a cantar uma melodia". (begin)

Consideraremos neste trabalho somente a posição $\mathrm{Asp}_{\text {InceptiveII }}$, segundo a qual é marcado o início de um evento télico em seu ponto inicial natural. Na estrutura do Middlefield, temos a posição $\mathrm{Asp}_{\text {InceptivelI }}$ localizada em uma posição baixa precisamente, entre as posições $\mathrm{Asp}_{\text {CompletivelI }}$ e $\mathrm{Asp}_{\text {Completivel }}$, segundo a hierarquia da fig. 1. A emergência da leitura incoativa a partir da posição pré-verbal do adjunto temporal se deve a um movimento do VP com pied-piping do adjunto de medida no modo pictures-of-whom (no espírito de Cinque, 2017), como vemos na representação da derivação da figura 3, mais adiante. Consideremos, a esse propósito, os exemplos abaixo:

\section{João em 10 minutos lavou a louça.}

19. A menina em 20 minutos ganhou o jogo de xadrez.

No exemplo (19), a posição do adjunto temporal de medida não interfere na possibilidade de interpretação da sentença, que terá somente a leitura télica com alcance do telos dado pelo sintagma de medida do adjunto temporal, no caso "20 minutos". Diferentemente, no exemplo (18), a posição pré-verbal, entre sujeito e VP, do adjunto temporal de medida, viabiliza a leitura incoativa. Este movimento é ilustrado pela figura abaixo:

${ }^{31}$ Não entraremos nos pormenores da ontologia da posição do Sujeito em Cartografia. A esse respeito, ver Quarezemin e Cardinaletti (2017).

${ }^{32}$ Estamos tomando como base os trabalhos de Cinque (1999 e 2006). A diferença entre os verbos "start" e "begin", mencionadas pelo autor, não será considerada neste trabalho. Contudo, talvez essa diferença trazida por Cinque, e que o autor, para o inglês, remete aos dois tipos de verbo "começar", tenha relação com o tipo de evento que se começa a fazer, no caso, "fazer a barba" e "construir uma casa". Tal singularidade entre esses eventos pode ser discutida em trabalhos futuros. 


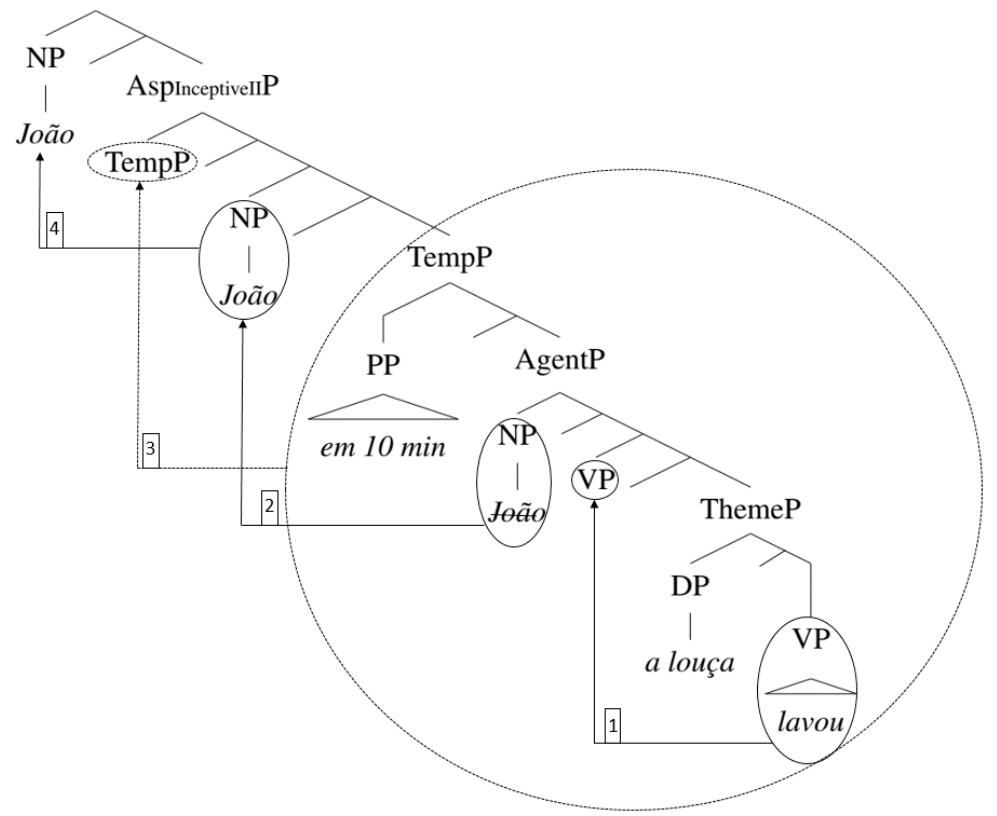

Figura 3. Da derivação de (18) - Fonte: Elaboração própria

Temos, na fig. 3, um movimento diferente do VP (em relação ao movimento do tipo whose-pictures, responsável pela derivação da leitura télica da figura 2). Temos aqui, como já mencionado anteriormente, a subida de TempP, i.e., de todo o bloco que tem TempP como raiz. A possibilidade da leitura incoativa deriva, portanto, desses ingredientes: soldagem do circunstancial no especificador de TempP e subida dessa projeção - após a extração do sujeito (passo descrito em "2", na fig. 3) - ao especificador do núcleo de aspecto inceptivo soldado acima (numa sorte de movimento de VP com pied-piping no modo pictures-of-whom do adjunto).

Temos então que, dependendo do tipo de evento combinado com o adjunto temporal de medida "em x tempo", serão acionadas posições diferentes do Middlefield, em que correm a valoração dos traços esperados, os quais tem relação direta com as possíveis interpretações que cada combinação faz emergir.

As discussões avançadas neste trabalho - a respeito da possível contribuição do adjunto temporal de medida, tendo em vista a hipótese B (descrita na seção anterior) - se mostram importantes quando, por exemplo, levamos em conta construções como as abaixo:

20. João em 10 minutos fez a lição de casa em 1 hora.

21. Suzana em 15 minutos fez a lição de casa por 1 hora.

22. Tamara em 20 minutos jogou tênis por 2 horas. 
Os exemplos acima mostram que sentenças com dois adjuntos temporais parecem possíveis e não muito estranhas no português brasileiro. Por exemplo, se considerarmos que João ou Suzana acabaram de chegar em casa da escola e levaram 10 minutos e 15 minutos, respectivamente, para começarem a fazer a lição de casa, as sentenças (20) e (21) parecem possíveis. É importante notar que o primeiro adjunto temporal, em posição pré-verbal, diz respeito ao tempo que levou para o predicado denotado na sentença iniciar (leitura incoativa); já o segundo adjunto temporal, se relaciona diretamente com o tempo do evento da sentença, sendo que, em (20), João fez a lição de casa e a terminou em 1 hora (leitura télica) e, em (21), Suzana fez a lição de casa por 1 hora, mas não necessariamente a fez completamente, ou melhor, o telos não foi alcançado necessariamente (leitura de detelicização de evento télico). Para o evento de atividade em (22), temos uma interpretação incoativa com o primeiro adjunto e uma interpretação de duração de evento com o segundo.

Além disso, algo que será aprofundado de maneira mais detalhada em trabalhos posteriores, é a possibilidade ou não da presença de cada adjunto temporal em certas posições sintáticas, como nos exemplos abaixo:

23. *João por 10 minutos fez a lição de casa em 1 hora.

24. * Suzana por 15 minutos fez a lição de casa por 1 hora.

25. *Tamara por 20 minutos jogou tênis por 2 horas.

Nas sentenças (23-25), vemos que, quando temos em posição pré-verbal um adjunto temporal que denota a duração do evento, no caso "por x tempo", não fazendo qualquer menção a seu fim, as sentenças parecem estranhas quando combinadas com um segundo adjunto em posição default.

À guisa de conclusão, a combinação de dois adjuntos temporais na mesma estrutura sentencial parece ser possível no português brasileiro; contudo, essa combinação pode estar na dependência direta do tipo de adjunto temporal que ocupa uma posição sintática específica.

\section{CONSIDERAÇÕES FINAIS}

Argumentando em favor da hipótese B, vimos que as projeções dadas na hierarquia universal (Cinque, 1999) do Programa Cartográfico parecem ser suficientes para capturarmos as possíveis interpretações dos adjuntos temporais de medida do tipo de "em $x$ tempo".

Mostramos que eventos do tipo accomplishment, quando combinados com o adjunto temporal de medida "em x tempo", valoram seus traços em duas posições

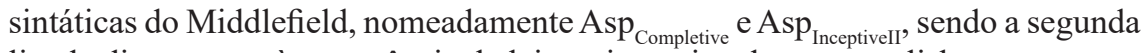
ligada diretamente à emergência da leitura incoativa dos accomplishments. 
Por sua vez, a interpretação do adjunto temporal de medida "em x tempo" em co-ocorrência com eventos do tipo achievement é resultado da valoração dos traços associados a $\mathrm{Asp}_{\text {Completive }}$.

A combinação de ingredientes cartográficos (uma única estrutura hierárquica de base) e mecanismos básicos de construção das estruturas (Soldagem e Movimento, como é praxe no programa minimalista) favorecem um mapeamento já direto da Narrow Syntax à LF. Isso fica claro nas discussões aqui avançadas, envolvendo o adjunto de medida temporal "em x tempo": não obstante a poder ser lexicalizado (aparentemente) em mais de uma posição na estrutura, os significados gerados estão numa dependência estrita das projeções funcionais acionadas nas leituras télica e incoativa.

\section{REFERÊNCIAS}

BASSO, R. 2007. Telecidade e detelicização: semântica e pragmática do domínio tempo-aspectual. Dissertação (Mestrado em Linguística), UNICAMP.

BASSO, R. M., e BERGAMINI-PEREZ, J. F. 2017. A Semântica de vetores: uma proposta de análise para os adjuntos temporais. Curitiba, Revista Letras (UFPR), n. 96, pp. 33-53.

BASSO, R. M. e BERGAMINI-PEREZ, J. F. 2016. Adjuntos temporais e measure phrases: uma proposta semântica. Campinas, Cadernos de Estudos Linguísticos, v. 58, n. 2, pp. 345-367.

BELLETTI, A. 1990. Generalized Verb Movement. Turim: Rosenberg \& Sellier.

CHOMSKY, N. The Minimalist Program. Massachusetts: MIT Press, 1995.

CINQUE, G. 1997. Adverbs and Functional Heads: a Cross-Linguistic perspective. Venezia: Centro Linguistico Interfacoltà, Università degli studi di Venezia.

CINQUE, G. 1999. Adverbs and Functional Heads: A Cross-linguistic Perspective. New York: OUP.

CINQUE, G. 2004. Issues in adverbial syntax. Lingua, 114 (6), p. 683-710.

CINQUE, G. 2006. Restructuring and Functional Heads. Vol.4, New York: OUP.

CINQUE, G. 2017. On the status of functional categories (heads and phrases). Language and Linguistics, 18(4), p. 521-576.

EMONDS, J. 1978. The Verbal Complex V'-V in French. Linguistic Inquiry, 9, p. 151-175.

GALVES, C. 2001. Ensaios sobre as gramáticas do português. Campinas: Editora da UNICAMP.

KAYNE, R.S. 2005. Movement and Silence. New York: Oxford University Press, 2005.

LIMA, B.F. 2020. A cartografia das exclamativas-wh em português brasileiro: categorias e hierarquias. Dissertação (Mestrado em Linguística), UNICAMP. 
POLLOCK, J-Y. 1989. Verb Movement, Universal Grammar, and the Structure of IP. Linguistic Inquiry, vol. 20(3), pp. 265-424.

QUAREZEMIN, S.; CARDINALETTI, A. 2017. Non-topicalized preverbal subjects in Brazilian Portuguese, compared to Italian. Rivista Annali di Ca' Foscari. Serie occidentale, vol. 51, pp. 383-409.

RIZZI, L. 1997. The Fine Structure of Left Periphery. In: Haegman, L. (Ed.). Elements of Grammar. Dordrecht, Kluwer Academic Publisher.

RIZZI, L. 2004. Locality and Left Periphery. In: Belletti, A. (Ed.) Structures and Beyond: The Cartography of Syntactic Structures, vol.3. New York/Oxford: Oxford University Press, pp. 223-251.

ROY, I. e SVENONIUS, P. 2009. Complex prepositions in Autour de la Préposition, edited by J. François, É. Gilbert, C. Guimier, and M. Krause. Presses universitaires de Caen, pp. 105-116.

SCHIFANO, N. 2018. Verb Movement in Romance. New York, Oxfor: Oxford University Press.

SILVA, G.V. 2001. Word Order in Brazilian Portuguese. Berlin: Mouton de Gruyter.

TESCARI NETO, A. 2013. On Verb Movement in Brazilian Portuguese: A Cartographic Study. Tesi (Dottorato di Ricerca in Scienze del Linguaggio), Università Ca'Foscari di Venezia.

TESCARI NETO, A. 2015. Por que advérbios altos não são diagnósticos para movimento do verbo?. Lingüística (online), vol. 31, n. 2, pp. 27-46.

TESCARI NETO, A. 2019. Da posição do verbo temático em cinco variedades ibéricas. Revista de Estudos da Linguagem, vol. 27(2), pp. 737-770.

VENDLER, Z. 1957. "Verbs and Times". Philosophical Review, pp. 143-160.

Recebido: $16 / 3 / 2020$

Aceito: 9/7/2020

Publicado: 10/8/2020 